\title{
Mapping Global GDP Distribution
}

\author{
Fubao Sun, Tingting Wang, and Hong Wang
}

\section{Introduction}

Socioeconomic projections are crucial in climate change impact, mitigation, and adaptation research and risk assessments for future scenarios (O’Neill et al. 2014). The climate projections in the Scenario Model Intercomparison Project (ScenarioMIP) are formed based on different Shared Socioeconomic Pathways (SSPs) and specific Representative Concentration Pathways (RCPs) of Phase 6 of the Coupled Model Intercomparison Project (CMIP6) (O’Neill et al. 2016). The development of research on future socioeconomic impact and on reduction in exposure and vulnerability and increase in resilience to climate extremes (Wilbanks and Ebi 2014; Chen et al. 2020) can benefit from more spatially explicit socioeconomic data of higher spatial resolution and precision under five SSPs (O'Neill et al. 2016).

The GDP is a standard socioeconomic indicator in economic development assessment within and across countries

\footnotetext{
Authors: Fubao Sun, Tingting Wang, Hong Wang. Map Designers: Qingyuan Ma, Jing'ai Wang, Ying Wang. Language Editor: Tingting Wang.
}

F. Sun $(\bowtie) \cdot T$. Wang $\cdot$ H. Wang

Key Laboratory of Water Cycle and Related Land Surface Processes, Institute of Geographic Sciences and Natural Resources Research, Chinese Academy of Sciences, Beijing, 100101, China e-mail: sunfb@igsnrr.ac.cn

\section{F. Sun}

State Key Laboratory of Desert and Oasis Ecology, Xinjiang Institute of Ecology and Geography, Chinese Academy of Sciences, Urumqi, 830011, China

Akesu National Station of Observation and Research for Oasis Agro-ecosystem, Akesu, 843000, China

College of Resources and Environment, University of Chinese Academy of Sciences, Beijing, 100049, China
(Nordhaus 2011; Kummu et al. 2018; Tobias 2018), and is usually provided at the national scale from several global institutions such as the World Bank, the Organization for Economic Co-operation and Development (OECD), and so on. But regional GDP data at a finer spatial resolution (e.g., at the state, city, or county level) are often unavailable, especially in many developing countries (Nordhaus 2011; Kummu et al. 2018; Huang et al. 2018). The recent development of satellite-derived nighttime light (NTL) images and gridded population data helps disaggregate global and regional GDP into gridded datasets at various spatial scales (Doll et al. 2006; Ghosh et al. 2010; Nordhaus 2011; Zhao et al. 2017) to support current research on climate change and risk assessments. These disaggregated GDP data are, however, often biased due to saturation problem of NTL images or the assumption of even GDP per capita within a given administrative boundary when using population datasets. Besides, the global gridded GDP projections of future SSPs are rather limited (Jones and O'Neill, 2016; Jiang et al. 2017,2018; Kummu et al. 2018).

The objective of this research is to present a set of spatially explicit global gridded GDP data that are comparable and represent substantial long-term changes of GDP for both the historical period and for future projections under five SSPs (Wang and Sun 2020). 


\section{Method}

\subsection{Global GDP Distribution}

National GDP purchasing power parity (PPP) of 195 countries/ regions for 2005 was obtained from Geiger (2018), which was mainly from the Penn World Tables, and data of missing countries were taken from another version and the World Bank after rescaling from 2011 to 2005 PPP in U.S. dollars.

\subsection{Population-Based GDP Disaggregation}

Broad literature has emphasized the role of human capital as a key driver of economic growth, and population can well capture the link between the human and economic systems in various models. Hence, gridded population dataset has been widely applied in spatial allocation of global and regional GDP based on several well-known population datasets, e.g., the LandScan Global Population database, the Gridded Population of the World dataset, Version 4 (GPWv4), the Worldpop, and so on. The GDP disaggregation based on population dataset (denoted as $G D P_{P o p}$ ) can be expressed as.

$$
\mathrm{GDP}_{\text {pop }}=\text { Pop }_{\text {pixel }} \times \mathrm{P}_{\text {cap }}=\mathrm{Pop}_{\text {pixel }} \times \frac{\mathrm{GDP}_{\mathrm{i}}}{\mathrm{Pop}_{\mathrm{i}}}
$$

where $G D P_{p o p}$ and $P o p_{\text {pixel }}$ are the GDP and population in each pixel in administrative unit $i$, and Pcap is the GDP per capita, which is the ratio of GDP total $\left(G D P_{i}\right)$ to population total $\left(P o p_{i}\right)$ in a given administrative area $i$.

\subsection{NTL-Based GDP Disaggregation}

Numeric modelings have shown that the satellite-derived NTL data are well correlated with GDP at all examined scales, and such data has been widely used in the spatial allocation of GDP across the globe. The Defense Meteorological Satellite Program's Operational Linescan System (DMSP-OLS) NTL images in 2005 (average visible, stable lights, and cloud-free coverages, satellites F14 and F15 simultaneously collected global NTL images, and data from F15 were chosen as newer sensor would have less degradation of data quality) were used to disaggregate global GDP to a spatial resolution of 30 arc seconds. Based on the results of relevant studies (Ghosh et al. 2010; Nordhaus 2011; Zhao et al. 2017; Eberenz et al. 2020), the GDP totals were directly distributed to each pixel in proportion to the $\mathrm{DN}$ values of pixels in a given administrative area, and the NTL-based GDP disaggregation (denoted as $\left.G D P_{L i t}\right)$ can be described as

$$
\mathrm{GDP}_{\text {Lit }}=\mathrm{GDP}_{\text {per_light }} \times \mathrm{DN}_{\text {pixel }}=\frac{\mathrm{GDP}_{\mathrm{i}}}{\mathrm{SL}_{\mathrm{i}}} \times \mathrm{DN}_{\text {pixel }}
$$

where $G D P_{i}$ is the total GDP, $S L_{i}$ is the sum of DN values, $G D P_{\text {per_light }}$ is the constant in administrative unit $i$, and $D N_{\text {pixel }}$ and $G D P_{\text {pixel }}$ are the DN value and corresponding GDP in each pixel in administrative unit $i$.

The saturation problem in the DMSP-OLS NTL images, however, has resulted in biased GDP disaggregation (Zhao et al. 2017). Zhao et al. (2017) improved its accuracy by incorporating the gridded population data into NTL-based GDP disaggregation in each pixel, and Eberenz et al. (2020) further improved this method. By multiplying the NTL image with the LandScan population data, a LitPop image was produced based on Eq. (3), which was then used to spatialize GDP at the global scale (denoted as $\mathrm{GDP}_{\text {Lit-Pop }}$ ) using Eq. (4):

$$
\begin{gathered}
\text { LitPop }_{\text {pix }}=\left\{\begin{array}{cc}
\text { Pop } & \text { Lit }=0 \\
\text { Lit } \cdot \text { pop } & \text { Lit }>0 \& \text { Pop }>0 \\
\text { Lit } & \text { Pop }=0
\end{array}\right. \\
\text { GDP }_{\text {LitPop }}=\frac{\text { GDP }_{i}}{\mathrm{SLP}_{\mathrm{i}}} \times \text { LitPop }_{\text {pix }}
\end{gathered}
$$

where LitPop pix is the GDP value of each pixel of the LitPop data and $S L P_{i}$ is the sum of values of the LitPop image in administrative unit $i$.

The technical flow of mapping global GDP is shown in Fig. 1.

\section{Results}

To examine the performance of the $G D P_{P o p}, G D P_{l i t}$, and $G D P_{\text {LitPop }}$, comparisons were made between GDP in 205 countries using the World Bank data (Fig. 2a); in 476 states (provinces) of 36 OECD countries, the United States, and China (Fig. 2b); and in 5231 counties in the United States and China (Fig. 2c) in 2005 that are spatially joined to the corresponding GIS-based administrative boundaries, respectively. The comparisons show that the accuracy of the three disaggregated GDP datasets decreases with the change 
Fig. 1 Technical flowchart of mapping global GDP

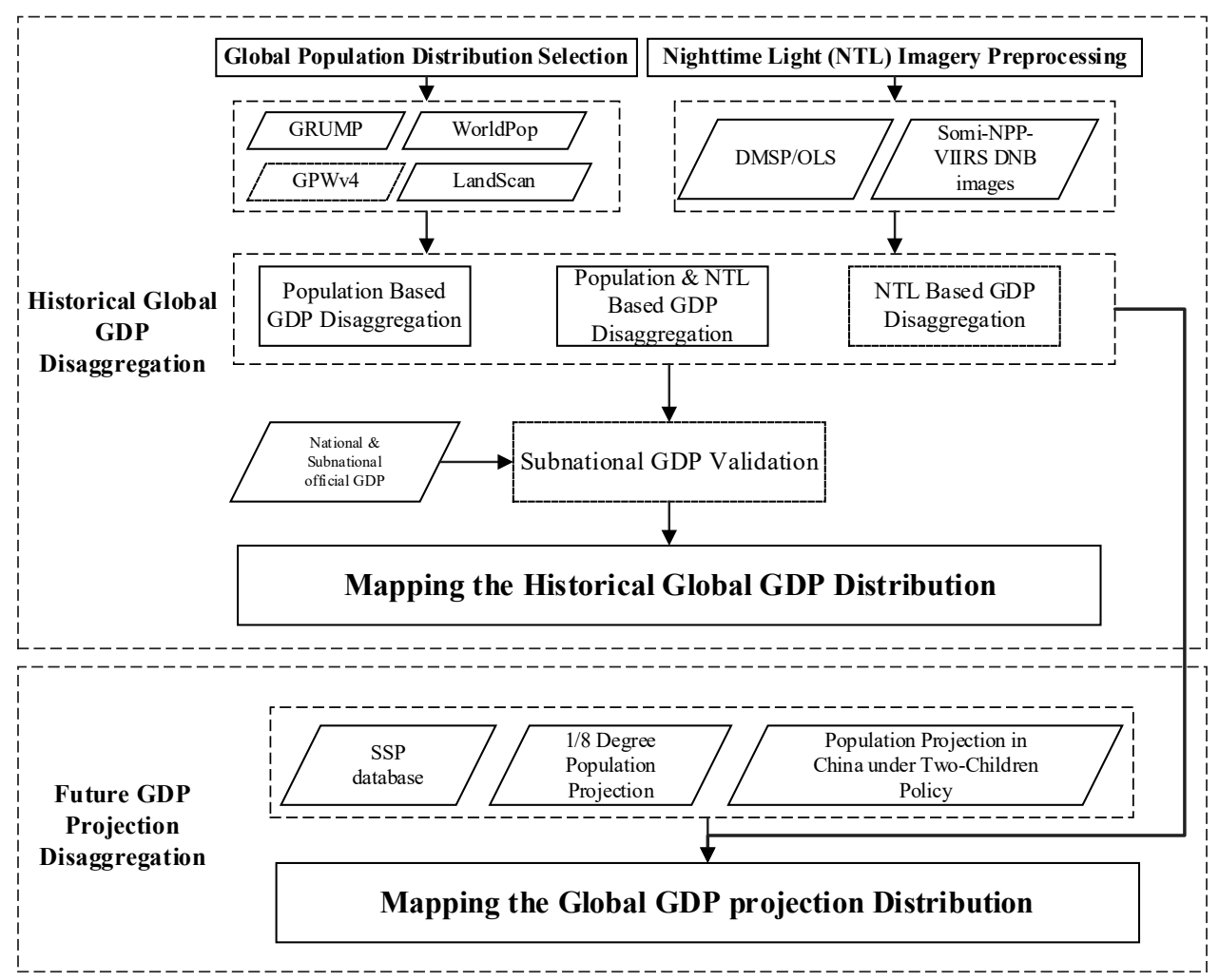

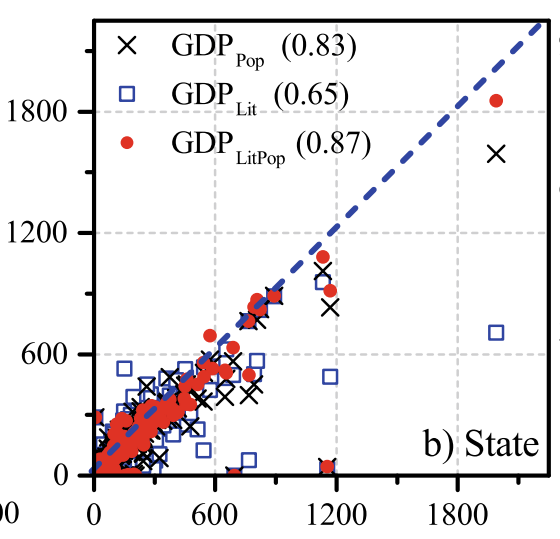

Official GDP (GRP) (billion USD)

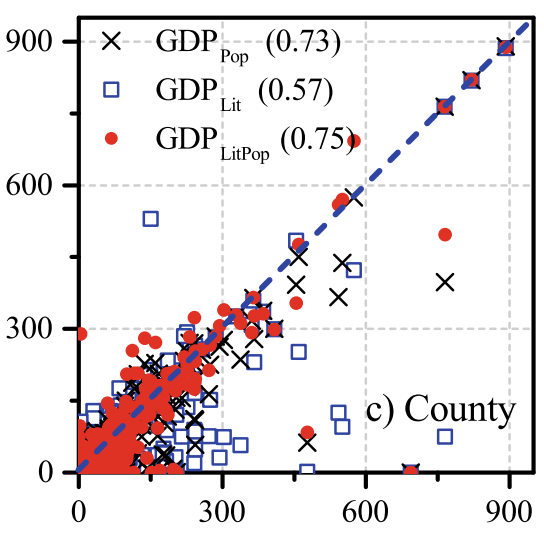

Fig. 2 Comparison between official GDP and disaggregated results at the national a, state b, and county $\mathbf{c}$ scales in 2005, using population-based disaggregation method, NTL-based approach, and LitPop approach, respectively, and the value in each brackets is their corresponding $\mathrm{R}^{2}$ 
Table 1 GDP statistics (trillion USD in 2005 PPP)

\begin{tabular}{|c|c|c|c|c|c|c|c|}
\hline & & $\begin{array}{l}\text { High } \\
\text { income }\end{array}$ & $\begin{array}{l}\text { Upper } \\
\text { middle } \\
\text { income }\end{array}$ & $\begin{array}{l}\text { Middle } \\
\text { income }\end{array}$ & $\begin{array}{l}\text { Low and } \\
\text { middle income }\end{array}$ & $\begin{array}{l}\text { Lower } \\
\text { middle } \\
\text { income }\end{array}$ & $\begin{array}{l}\text { Low } \\
\text { income }\end{array}$ \\
\hline \multicolumn{2}{|l|}{2005} & 37.01 & 10.73 & 0.27 & 1.14 & 0.55 & 0.09 \\
\hline \multirow[t]{3}{*}{2030} & SSP1 & 70.28 & 83.63 & 0.95 & 5.93 & 2.67 & 0.58 \\
\hline & SSP2 & 62.28 & 66.36 & 0.84 & 5.06 & 2.29 & 0.47 \\
\hline & SSP3 & 70.28 & 83.63 & 0.95 & 5.93 & 2.67 & 0.58 \\
\hline \multirow[t]{3}{*}{2050} & SSP1 & 95.07 & 136.08 & 1.95 & 14.90 & 8.69 & 2.72 \\
\hline & SSP2 & 85.06 & 101.78 & 1.64 & 11.27 & 6.33 & 1.71 \\
\hline & SSP3 & 68.63 & 76.92 & 1.46 & 7.96 & 4.51 & 1.11 \\
\hline
\end{tabular}

(decrease) of their spatial scales, and $G D P_{\text {LitPop }}$ is superior to $G D P_{P o p}$ and $G D P_{L i t}$ at the national, state (provincial), and county levels with clear advantages evaluated by their $\mathrm{R}^{2}$ and RMSE (Fig. 2).

Gross National Income (GNI) includes the nation's GDP plus the income from overseas sources, and has been widely used to measure and track a nation's wealth from year to year. Based on GNI per capita (current international dollars in PPP) in 2019 level from the World Bank, the global and regional GDP growth depicts major differences under the three SSP scenarios in 2030 and 2050 by income level of countries (Table 1). For countries with lower middle income $(\leq 6761$ GNI per capita) and low income ( $\leq 2458$ GNI per capita), in 2030 the GDP is about 6 times that of 2005 for SSP1-3, and reaches as high as 30,19, and 12 times in 2050, respectively. In developed countries with high income ( $\geq 52,412$ GNI per capita), in 2030 the GDP will only be about 1.7-.9 times that of 2005, and increase to about 2.6, 2.3, and 1.8 times in 2050 for SSP1-3. Meanwhile, for countries with middle income ( $\leq 11,934$ GNI per capita) and low and middle income ( $\leq 10,937$ GNI per capita), in 2030 the GDP will be 3.5 and 6.2 times that of 2005, showing an unequal growth rate among regions. 


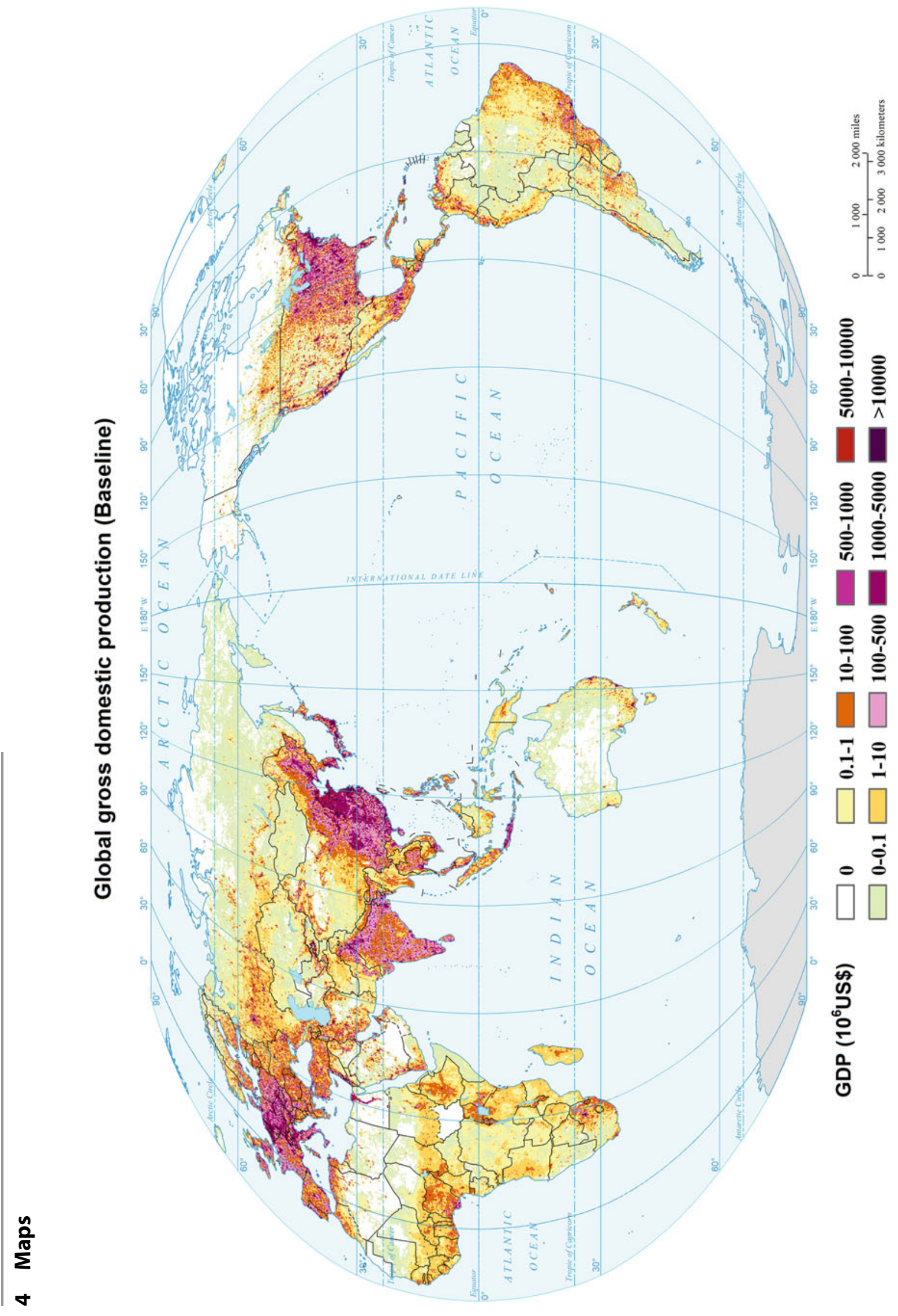


Projected global gross domestic production (2030, SSP1)

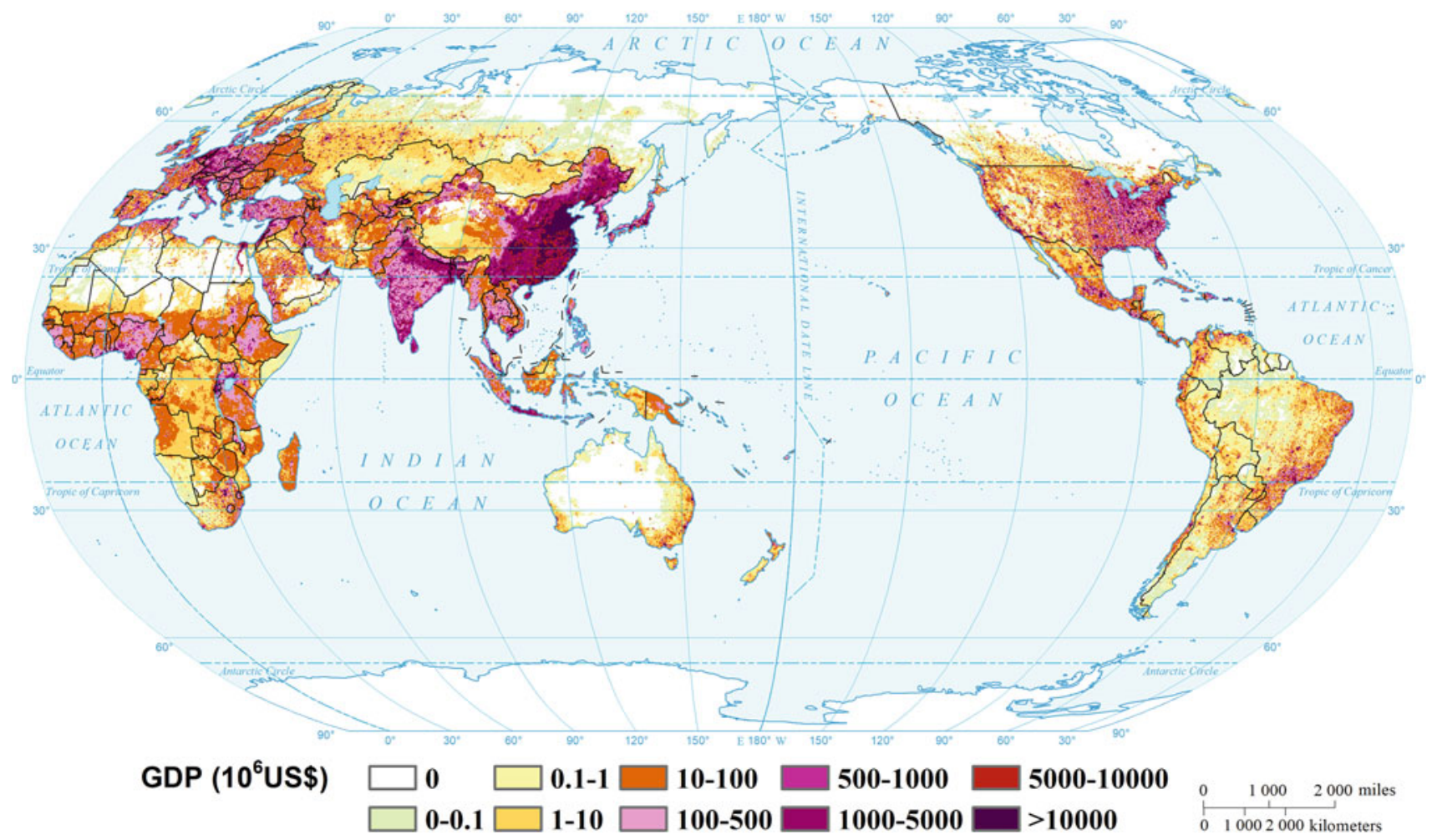

Projected global gross domestic production (2030, SSP2)

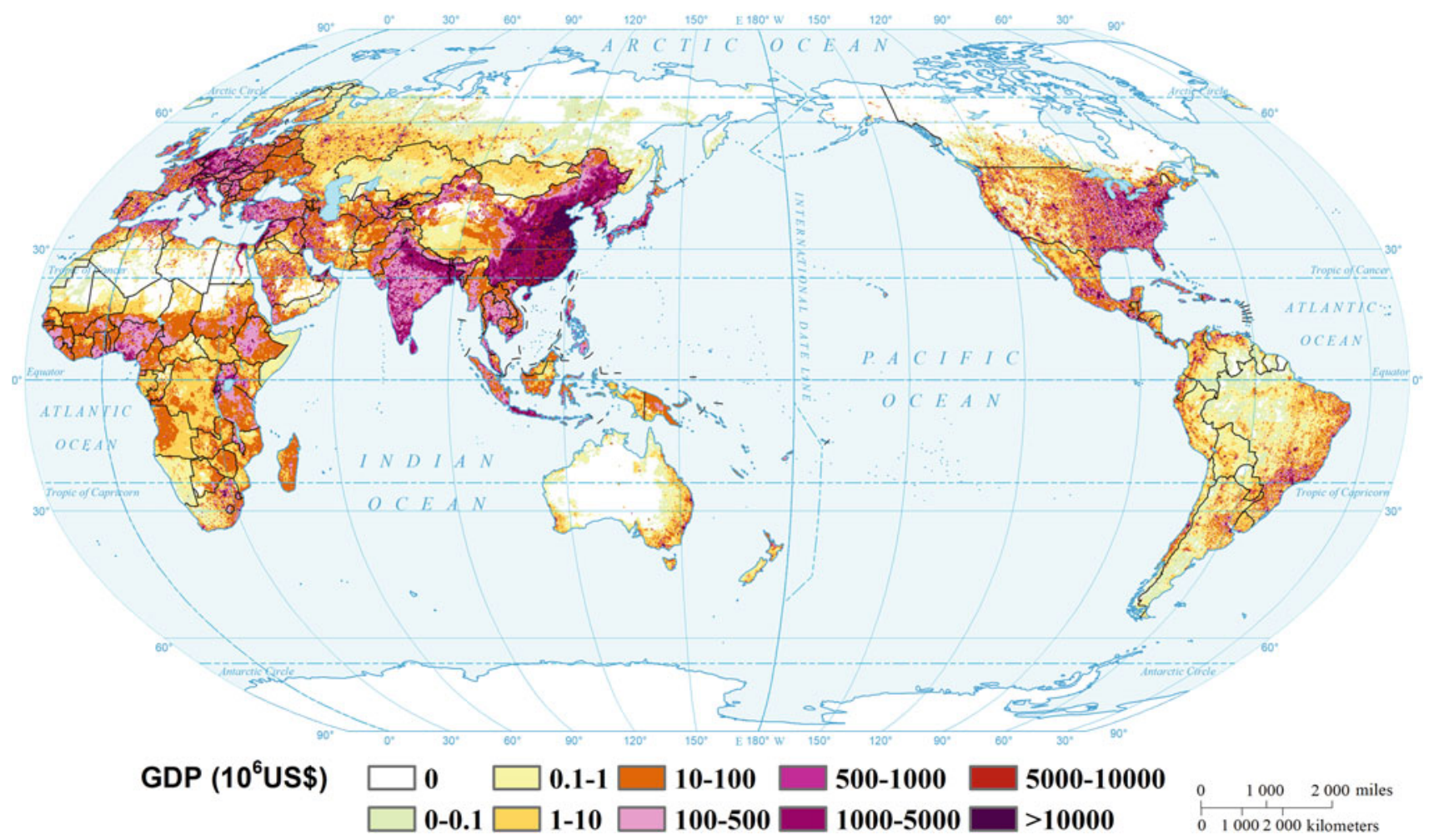




\section{Projected global gross domestic production (2030, SSP3)}

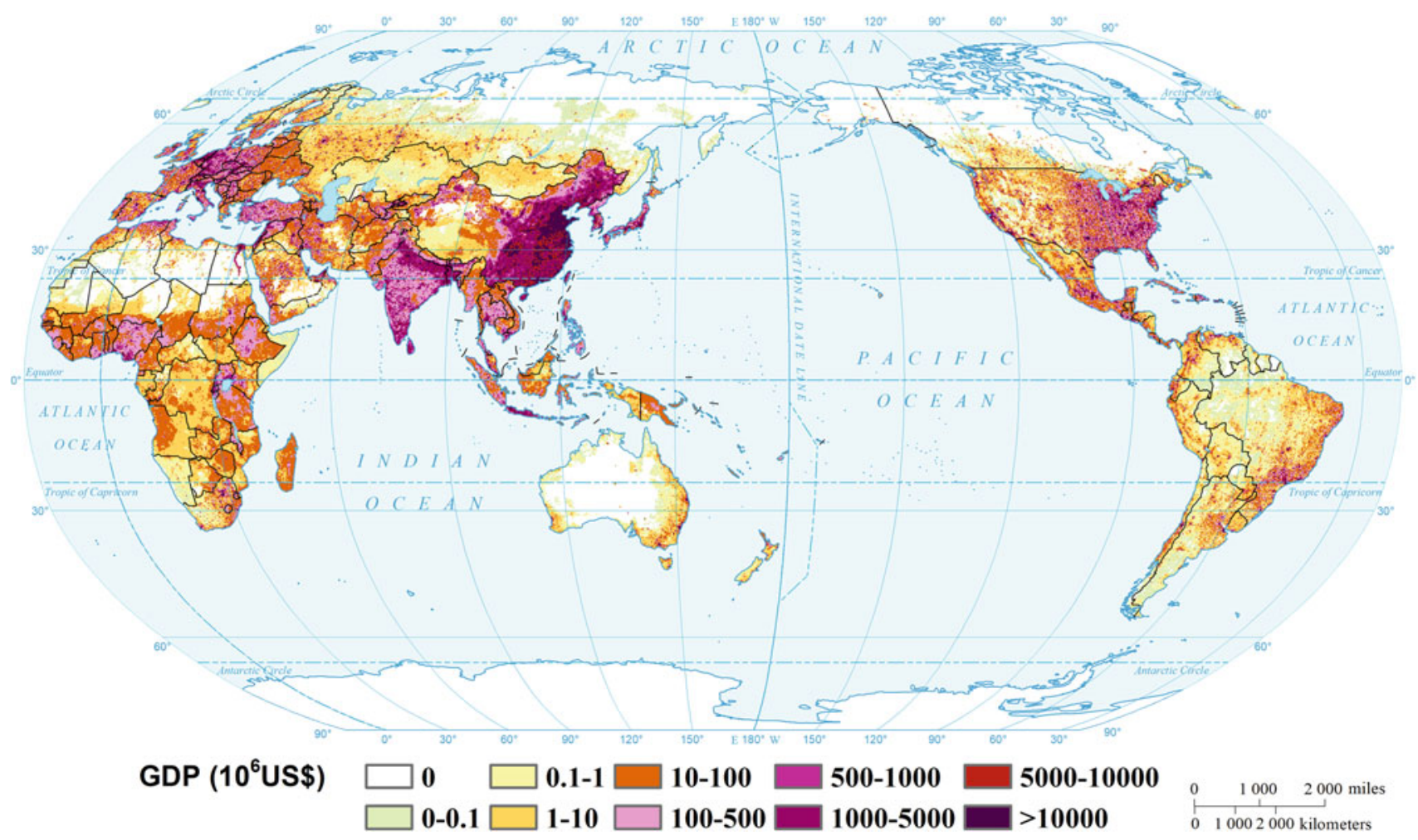

Projected global gross domestic production (2050, SSP1)

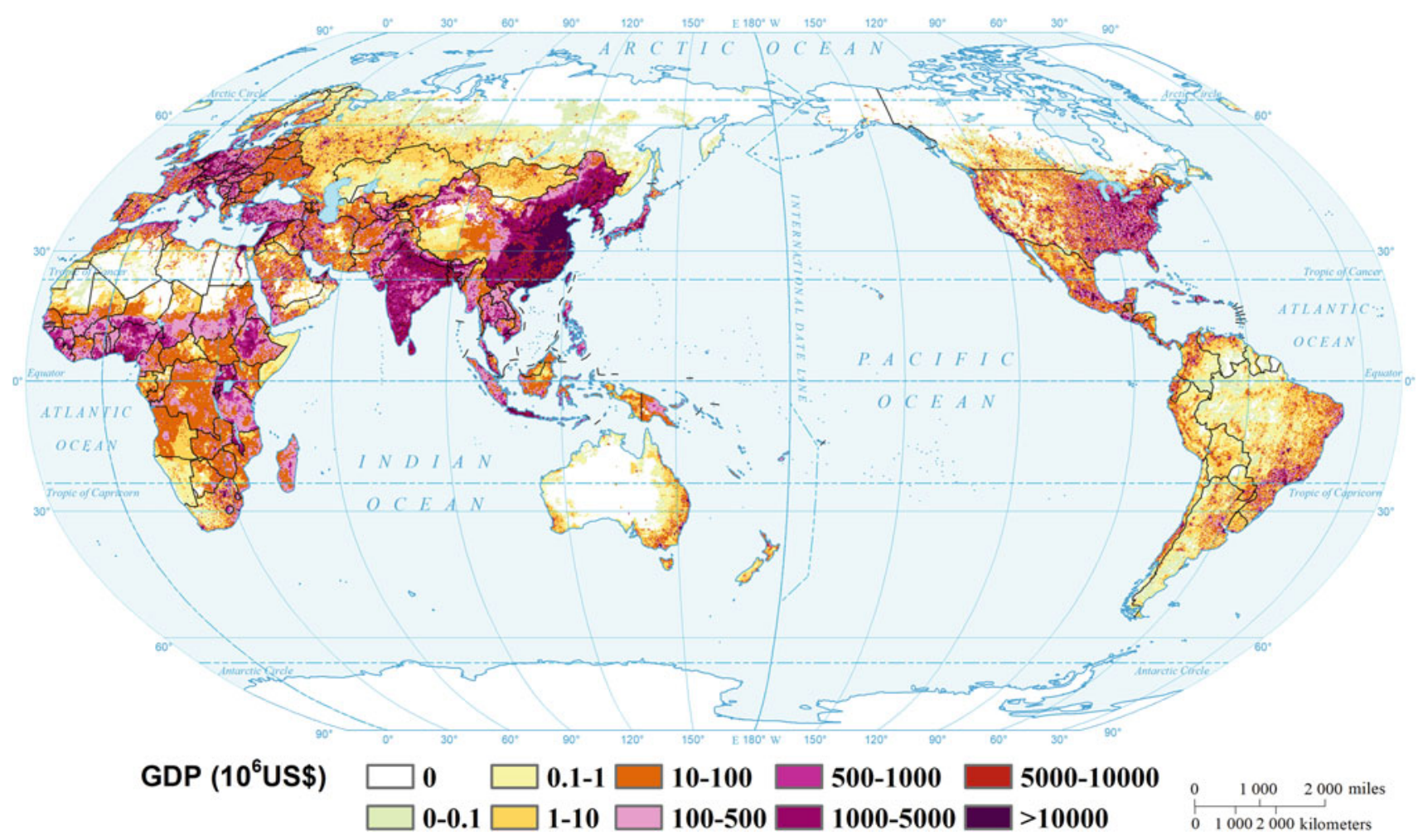


Projected global gross domestic production (2050, SSP2)

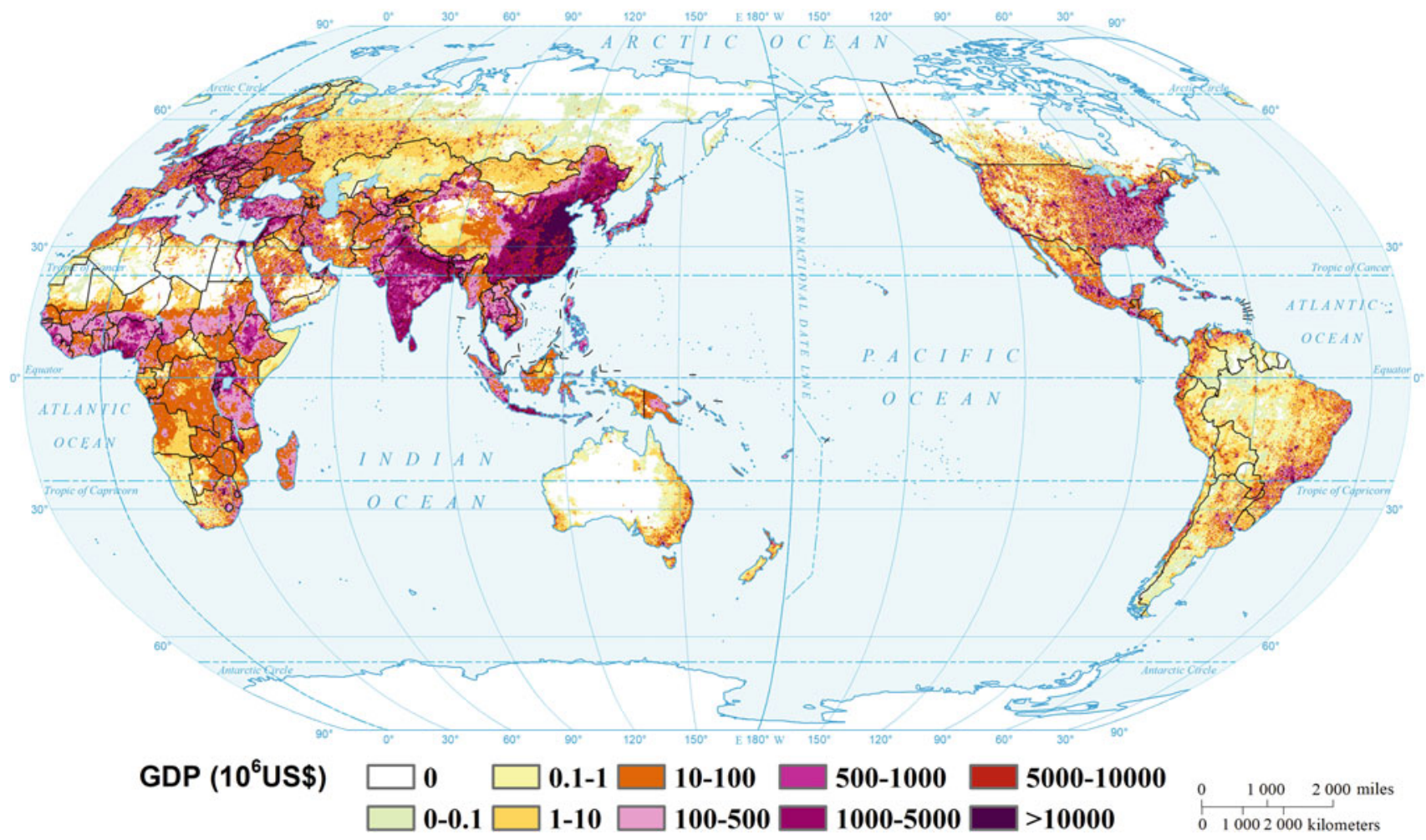

Projected global gross domestic production (2050, SSP3)

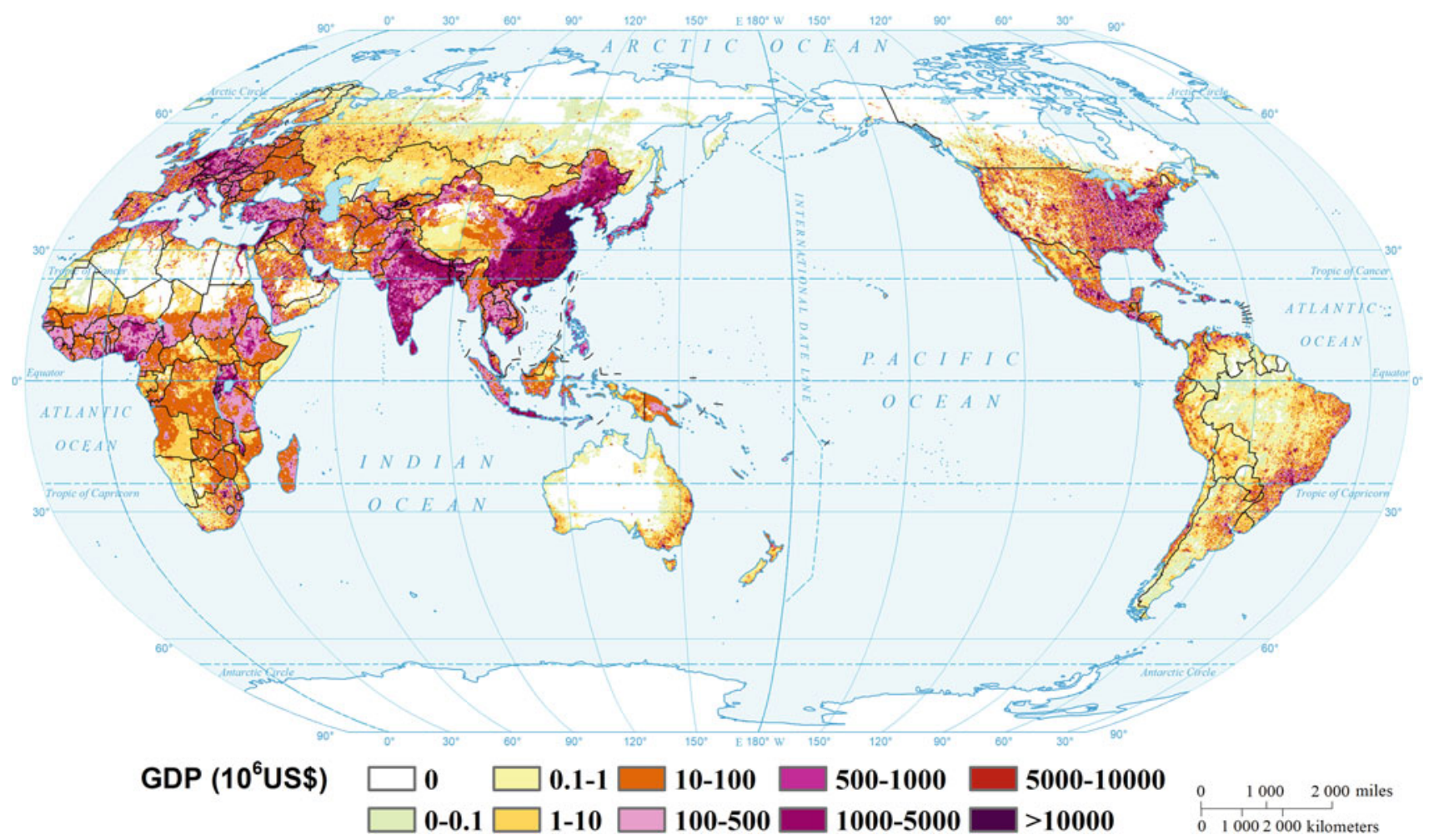




\section{References}

Chen, Q., T. Ye, N. Zhao, M. Ding, and X. Yang. 2020. Mapping China's regional economic activity by integrating points-of-interest and remote sensing data with random forest. Environment and Planning B Urban Analytics and City Science 3: 1-19.

Doll, C.N.H., J.P. Muller, and J.G. Morley. 2006. Mapping regional economic activity from night-time light satellite imagery. Ecological Economics 57: 75-92.

Eberenz, S., D. Stocker, T. Rsli, et al. 2020. Asset exposure data for global physical risk assessment. Earth System Science Data 12: 817-833.

Geiger, T. 2018. Continuous national gross domestic product (gdp) time series for 195 countries: past observations (18502005) harmonized with future projections according to the shared socio-economic pathways (2006-2100). Earth System Science Data 10: 847-856.

Ghosh, T., R.L. Powell, C.D. Elvidge, K.E. Baugh, P.C. Sutton, and S. Anderson. 2010. Shedding light on the global distribution of economic activity. The Open Geography Journal 3: 147-160.

Huang, J., D. Qin, T. Jiang, Y. Wang, Z. Feng, J. Zhai, L. Cao, Q. Chao, $\mathrm{X}$. Xu, and G. Wang. 2019. Effect of fertility policy changes on the population structure and economy of China: From the perspective of the shared socioeconomic pathways. Earth's Future 7: 250-265.

Jiang, T., J. Zhao, L. Cao, Y. Wang, B. Su, C. Jing, R. Wang, and C. Gao. 2018. Projection of national and provincial economy under the shared socioeconomic pathways in China. Climate Change Research 14: 50-58.

Jiang, T., J. Zhao, C. Jing, L. Cao, Y. Wang, H. Sun, A. Wang, J. Huang, et al. 2017. National and provincial population projected to 2100 under the shared socioeconomic pathways in China. Climate Change Research 13: 128-137.
Jones, B., and B.C. O’Neill. 2016. Spatially explicit global population scenarios consistent with the shared socioeconomic pathways. Environmental Research Letters 11: 084003.

Kummu, M., M. Taka, and J.H. Guillaume. 2018. Gridded global datasets for gross domestic product and human development index over 1990-2015. Scientific Data 5: 180004.

Nordhaus, C.W.D. 2011. Using luminosity data as a proxy for economic statistics. Proceedings of the National Academy of Sciences of the United States of America 108: 8589-8594.

O'Neill, B.C., E. Kriegler, K. Riahi, K.L. Ebi, S. Hallegatte, T.R. Carter, R. Mathur, and D.P. Van Vuuren. 2014. A new scenario framework for climate change research: The concept of shared socioeconomic pathways. Climatic Change 122: 387-400.

O'Neill, B.C., C. Tebaldi, D.P. Van Vuuren, V. Eyring, P. Friedlingstein, G. Hurtt, R. Knutti, E. Kriegler, et al. 2016. The scenario model intercomparison project (ScenarioMIP) for CMIP6. Geoscientific Model Development 9: 3461-3482.

Tobias, G. 2018. Continuous national gross domestic product (GDP) time series for 195 countries: Past observations (18502005) harmonized with future projections according to the shared socio-economic pathways (2006-2100). Earth System Science Data 10: $847-856$

Wang, T., and F. Sun. 2020. Spatially explicit global gross cell product (GCP) data set consistent with the shared socioeconomic pathways. Zenodo, Dataset,. https://doi.org/10.5281/zenodo.5004249.

Wilbanks, T.J., and K.L. Ebi. 2014. SSPs from an impact and adaptation perspective. Climatic Change 122: 473-479.

Zhao, N., Y. Liu, G. Cao, E.L. Samson, and J. Zhang. 2017. Forecasting China's GDP at the pixel level using nighttime lights time series and population images. Mapping Ences \& Remote Sensing 54: 407-425.
Open Access This chapter is licensed under the terms of the Creative Commons Attribution 4.0 International License (http:// creativecommons.org/licenses/by/4.0/), which permits use, sharing, adaptation, distribution and reproduction in any medium or format, as long as you give appropriate credit to the original author(s) and the source, provide a link to the Creative Commons license and indicate if changes were made.
The images or other third party material in this chapter are included in the chapter's Creative Commons license, unless indicated otherwise in a credit line to the material. If material is not included in the chapter's Creative Commons license and your intended use is not permitted by statutory regulation or exceeds the permitted use, you will need to obtain permission directly from the copyright holder. 